Article

\title{
Soft Tissue Evaluation of an Immediate Esthetic Zone Single Implant with a Stereolithographic Guide Using 3D Reconstruction and a CAD/CAM Customized Titanium Anatomic Abutment
}

\author{
Tae-Heung Kim ${ }^{1}\left(\right.$, You-Kyoung $\mathrm{Oh}^{2}{ }^{2}$, Chang-Mo Jeong ${ }^{3}$, Edward Chengchuan Ko ${ }^{4}$, \\ George K. Sándor ${ }^{5}{ }^{-}$and Yong-Deok Kim ${ }^{6, *}$ \\ 1 Department of Oral and Maxillofacial Surgery, School of Dentistry, Pusan National University, \\ Yangsan 50612, Korea; taeheung121@gmail.com \\ 2 Department of Prosthodontics, School of Dentistry, Pusan National University, Yangsan 50612, Korea; \\ bluesky141@hanmail.net \\ 3 Department of Prosthodontics, School of Dentistry, Pusan National University, Dental and Life Science \\ Institute \& Dental Research Institute, Yangsan 50612, Korea; cmjeong@pusan.ac.kr \\ 4 Department of Oral and Maxillofacial Surgery, Kaohsiung Medical University, Kaohsiung 80708, Taiwan; \\ ko.edward.kaseizen@gmail.com \\ 5 Department of Oral and Maxillofacial Surgery, Oulu University Hospital and Medical Research Center, \\ University of Oulu, 90220 Oulu, Finland; sandor_george@hotmail.com \\ 6 Department of Oral and Maxillofacial Surgery, School of Dentistry, Pusan National University, \\ Dental and Life Science Institute \& Dental Research Institute, Yangsan 50612, Korea \\ * Correspondence: ydkimdds@pusan.ac.kr
}

Received: 3 January 2020; Accepted: 25 February 2020; Published: 2 March 2020

\begin{abstract}
The replacement of an unrestorable tooth with a single implant-supported prosthesis is a treatment with predictable and successful outcomes. The anterior maxilla region is a complicated site for such treatment, due to its esthetic, functional, and physiological sensitivity. The purpose of this study was to evaluate the changes in the soft tissue following an immediate implant procedure using guided surgery in combination with a computer-aided design and computer-aided manufacturing (CAD/CAM) customized titanium anatomic abutment in the esthetic zone. A total of 13 patients who had been treated with an immediate post-extraction implant placement and an immediate provisional restoration were included in the study. The changes in the soft tissue dimension, interdental papilla, and esthetic score were evaluated with a follow-up of at least one year. There was no significant change in the midfacial mucosal status when compared to the pre-treatment situation. The recession of the mesial papillary height was $0.32 \mathrm{~mm}$ and the distal papillary height was $0.10 \mathrm{~mm}$. The mean horizontal change in the labial mucosa was $0.32 \pm 0.83 \mathrm{~mm}$. There was no significant difference between the mesial papilla index and the distal papilla index. The pink esthetic score value prior to treatment was 11.16, and at one-year follow-up, 10.25. Within the limitations of this study, the immediate post-extraction implant placement procedure with a stereolithographic guide and a provisionalization with a CAD/CAM customized titanium anatomic abutment may be a treatment option with predictable outcomes for the replacement of teeth in the esthetic zone.
\end{abstract}

Keywords: immediate post-extraction implant placement; esthetic zone; pre-fabricated customized abutment; immediate provisionalization; guided implant surgery; stereolithography 


\section{Introduction}

The replacement of an unrestorable tooth with a single implant-supported prosthesis is a treatment with predictable and successful outcomes. The esthetic outcomes, as well as the functional and physiologic outcomes, are quintessential in the treatment of the anterior maxilla area [1-4]. After a tooth is extracted, the loss of the periodontal ligament lowers blood supply to the alveolar bone. The buccal plate of the alveolar bone is particularly affected, and this ultimately yields poor esthetic outcomes [5]. It is important to maintain the architecture of the fresh extraction socket for the immediate post-extraction implant placement in the esthetic zone [6,7]. Many studies have reported that an immediate implant placement and provisional restoration provide acceptable changes in the soft tissue and esthetic outcomes [8-13]. A correct fixture positioning, grafting technique, and immediate provisional restoration help achieve successful results in the esthetic zone [7,14-18].

With the advancement of computer-aided design and computer-aided manufacturing (CAD/CAM) technology in implant dentistry, various implant techniques developed. With three-dimensional (3D) scanning and computed tomography (CT) imaging data, a CAD program can be used to diagnose and virtually plan an implant placement. First, the implant crown can be designed and waxed up into the desired shape on the intraoral scanning or impression data. The virtual prosthesis is integrated with the cone beam computed tomography (CBCT) data, allowing the clinician to virtually plan the placement of the three-dimensional implant. Once the integrated plan is established, a stereolithographic surgical guide and a customized prosthesis can be pre-fabricated by using 3D printing technology [19].

Stereolithographic guides made by using a CAD/CAM scanning program allow the computer to transfer planned implants onto the surgical field. This can improve the precision of the implant placement, enables a non-invasive surgical procedure, reduces the time, and allows the pre-fabricated prosthesis to connect to the planned position immediately after a surgery [20-22].

Customized abutments can be designed with an anatomically ideal emergency profile. Recently, various methods for improving the stability of soft tissue around implants have been developed. For example, restoration with pre-fabricated provisionalization after immediate implant placement is known to help maintain the anatomical structure of the extraction socket [23-25].

The purpose of this study was to evaluate the changes in the soft tissue in patients who were treated with an immediate post-extraction implant placement using a stereolithographic guide and an immediate restoration with a CAD/CAM customized titanium anatomic abutment in the esthetic zone.

\section{Materials and Methods}

\subsection{Patients and Materials}

This retrospective clinical study was approved by the ethical committee of the Pusan National University Dental Hospital as institutional review board (IRB) number: PNUDH-2019-017, and it included patients treated with immediately placed dental implants and an immediate provisional restoration using a titanium anatomic abutment, between April 2017 and May 2018. The inclusion criteria were as listed below:

1. At least 18 years old

2. Both adjacent teeth are intact

3. Followed-up for at least 1 year after final restoration

\subsection{Exclusion Criteria Were as Listed Below}

1. Systemic bone disease

2. Recent orthodontic treatment

3. Presence of an acute infection around the tooth

4. Less than one full year of follow-up after definitive restoration 
Of the total 18 patients with dental implants, 13 were included in this retrospective study. The data were collected through a careful review of the patients' medical records, clinical photos, and radiographs.

The Osstem ${ }^{\circledR}$ TS III fixture and OneGuide system (Osstem, Korea) were used in this study. The fixture is a submerged type with an internal connection and it has a tapered body. The sizes of the implant fixtures were as follows: Nine had a diameter of $4 \mathrm{~mm}$, and four had a diameter of $3.5 \mathrm{~mm}$. Eight fixtures had a length of $13 \mathrm{~mm}$, and five fixtures had a length of $11.5 \mathrm{~mm}$.

\subsection{Preparation for Treatment}

The patients' CBCT data and study cast from the alginate impression obtained at the initial visit were sent to a technician. The study cast was scanned with a digital scanner and the abutment was designed using the CAD/CAM program (Dental System, 3Shape, Copenhagen, Denmark), which was incorporated into the scanner. The customized abutment and provisional restoration were designed to reconstruct the original anatomic contour of the gingiva. The level of the abutment collar was placed along the gingival contour, and it rehabilitated the emergence profile of the tooth. The abutment was fabricated using titanium milling. After designing the prosthesis for the planned location with $\mathrm{CAD} / \mathrm{CAM}$, a surgical guide was designed based on the CBCT data and manufactured by 3D printing (Stratasys, USA). The stereolithographic guide established the precise placement of the implant fixture at the intended location, which then made it possible for the abutment to connect as planned (Figure 1).

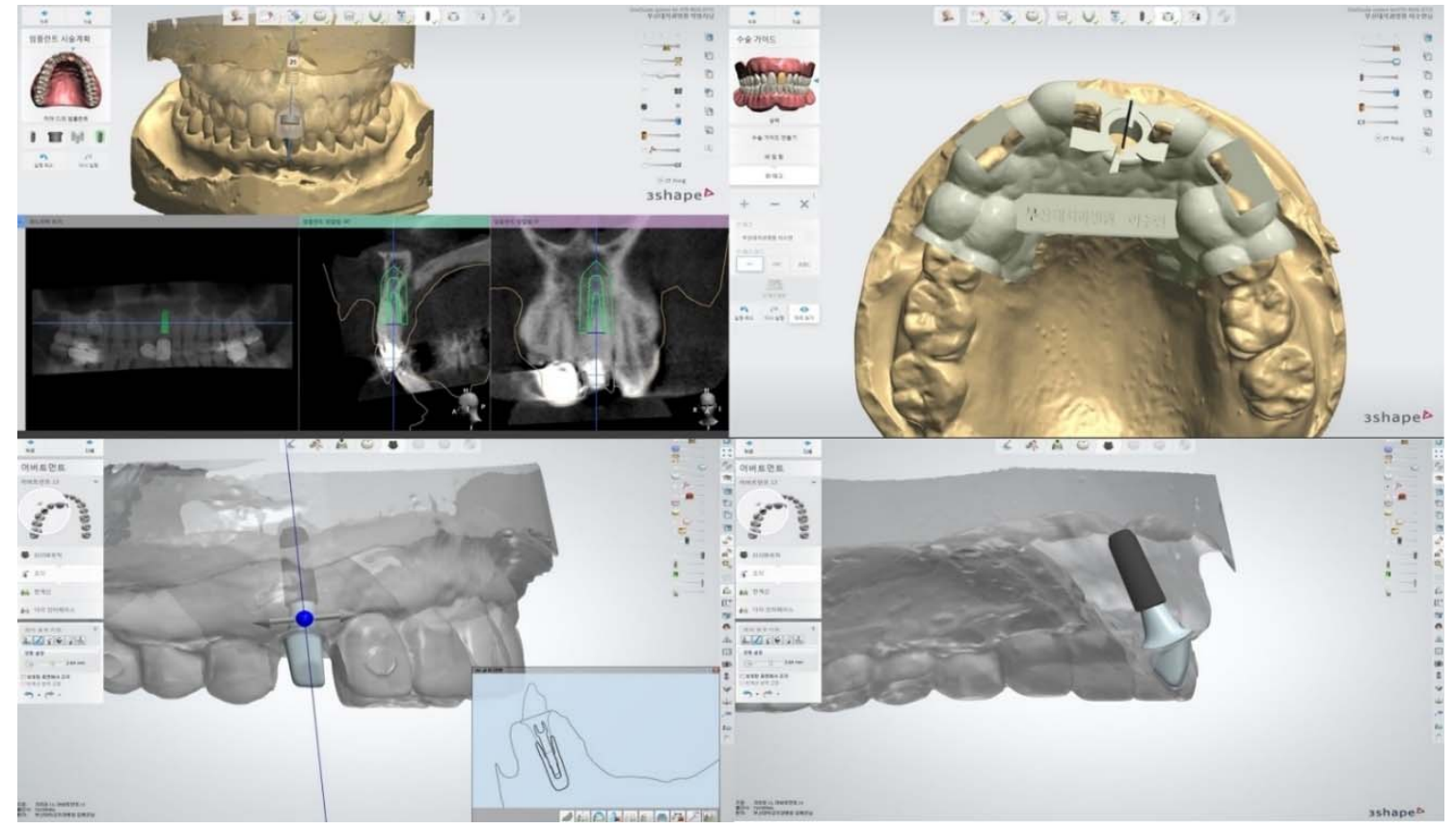

Figure 1. Design of a Stereolithographic Surgical Guide and Customized Abutment Using Computer-Aided Design and Computer-Aided Manufacturing (CAD/CAM).

\subsection{Surgical Procedure}

All surgical procedures were performed by one oral and maxillofacial surgeon under local anesthesia. Before the surgery, $0.02 \%$ chlorhexidine rinsing was performed. After obtaining informed consent, the atraumatic tooth extraction was performed using dental forceps without flap elevation. After curettage of the extraction socket, a saline irrigation was done. The prepared stereolithographic guide (Oneguide, Osstem, Korea) was placed in the oral cavity and fixed in the adjacent teeth. Prior to placing the fixture, the integrity of the buccal bone was verified by an intrasocket probing. Based on the CBCT data, the implant fixture (TS III, Osstem, Korea) was placed after drilling according to the height and diameter, as planned. Drilling was fully aided by metal sleeve components in the surgical 
guide. The implant fixture was placed $2 \mathrm{~mm}$ apical to the cementoenamel junction of the adjacent tooth. A torque of 30-40 N was obtained as a primary stability. The xenograft material (Bio-Oss, Geistlich, Vol Hussen, Switzerland) was filled when the gap between the fixture and the bone wall was of $2 \mathrm{~mm}$ or more. A pre-fabricated abutment was connected to the fixture after surgery. The instructions for post-operative care were thoroughly explained, and amoxicillin and nonsteroidal anti-inflammatory drugs (NSAIDs) were prescribed to be taken three times daily for five days. None of the patients complained of postoperative discomfort or pain.

\subsection{Restoration Protocol}

All teeth were restored with single implant restorations, and immediate provisional restorations were performed on the day of surgery. After placement of the fixture, a pre-fabricated titanium customized abutment was connected, and the provisional restoration was cemented using an interim cement (TempBond Clear; Kerr Corp, Orange, Calif) (Figures 2 and 3). All provisional restorations were adjusted to avoid occlusal contacts with antagonists in the centric occlusion and lateral movements after the placement.

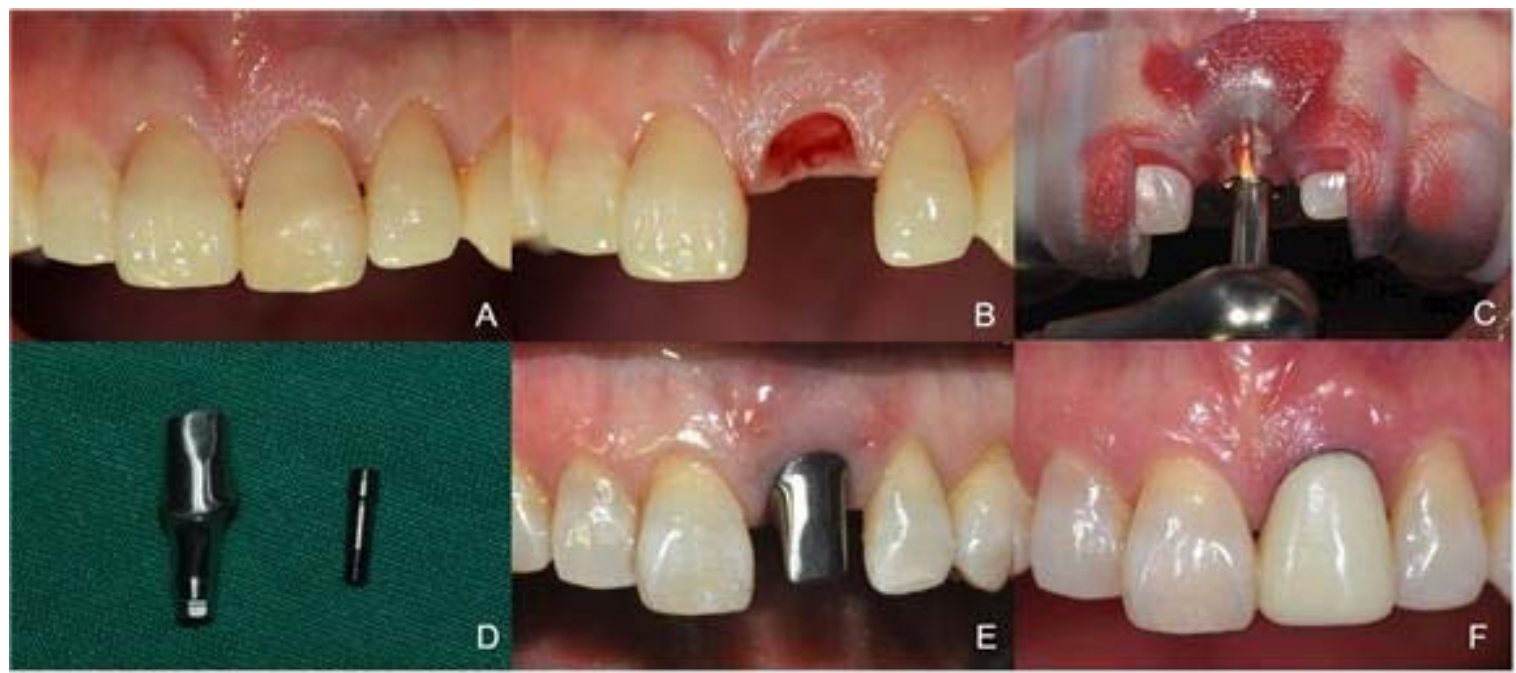

Figure 2. The Immediate Post-Extraction Implant Placement Using Guided Surgery with an Immediate Provisionalization (Case 1). (A) Before the Extraction of the Unrestorable Tooth, (B) After the Atraumatic Tooth Extraction, (C) Drilling with the Positioning of the Surgical Guide, (D) A Pre-Fabricated Customized Titanium Abutment, (E) The Abutment Supporting the Original Anatomic Contour of the Gingiva, (F) The Provisional Restoration was Cemented.

The definitive prosthesis was made after a minimum of 6 months. The final impressions were obtained at the fixture level for the fabrication of the final abutments and crowns. The final implant-supported prosthesis was made of porcelain fused to zirconia, porcelain fused to metal, porcelain fused to gold, or monolithic zirconia. The material of the final prosthesis was selected based on the preferences of the patients and the prosthodontists, according to each patient's situation. The final setting of an implant-supported prosthesis was done with an implant cement (Premier Implant Cement, Premier $®$ Dental Products Company, Plymouth Meeting, PA, USA). 


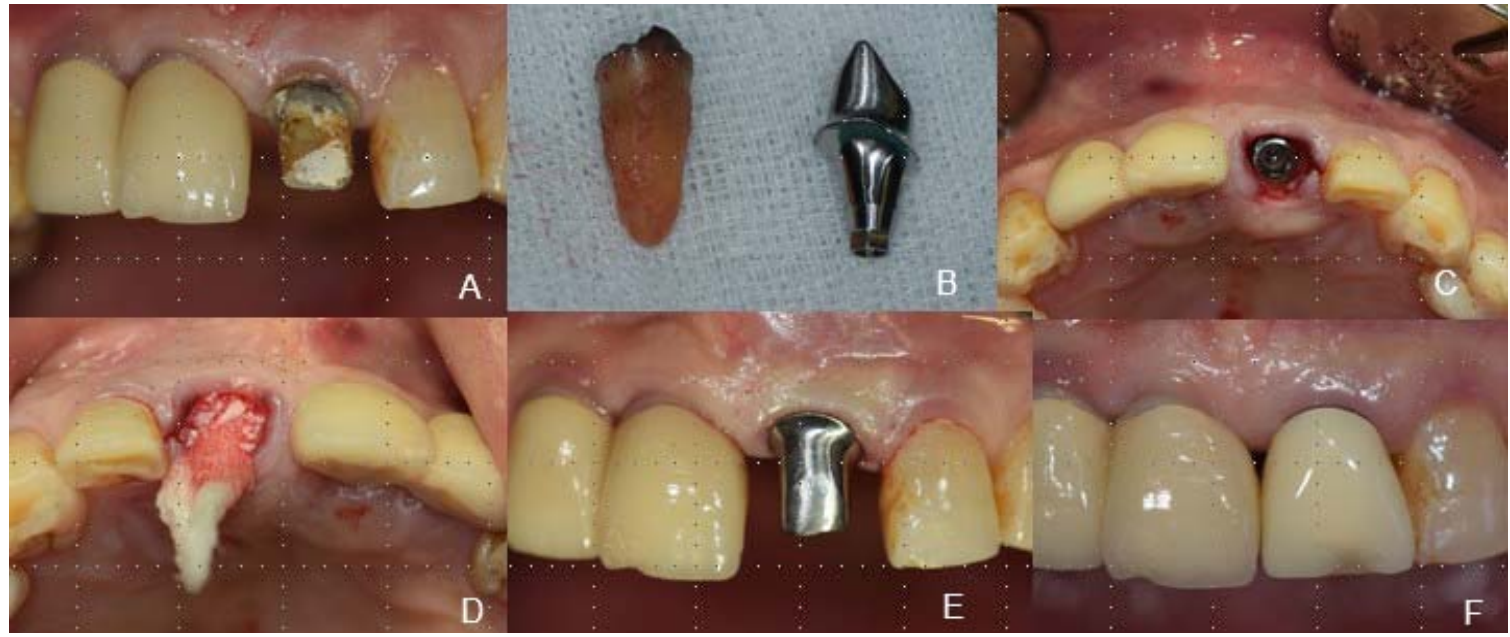

Figure 3. The Immediate Post-Extraction Implant Placement Using Guided Surgery with a Bone Graft and an Immediate Provisionalization (Case 2). (A) Before the Extraction of the Unrestorable Tooth, (B) The Extracted Tooth and a Pre-Fabricated Customized Titanium Abutment, (C) After Implant Placement, (D) The Gap Filled with Bio-Oss Between the Fixture and the Bone Wall, with a Piece of Cotton Applied for Bleeding Control, (E) The Abutment Supporting the Original Contour of the Gingiva and Capping the Grafted Material, (F) The Provisional Restoration was Cemented.

\subsection{Soft Tissue Measurement}

The soft tissue dimension data were collected from the study casts and follow-up casts. The changes in mesial papilla, distal papilla, and midfacial mucosa were measured with respect to the incisal edge level of the adjacent teeth. Each cast was also digitized using a digital scanner (Trios, 3shape, Copenhagen, Denmark), and digital cast models were superimposed using a best-fit algorithm on the Geomagic Control X program (version 2018.0.13D Systems, Cary, NC, USA). To evaluate the labial soft tissue volume change, the area of interest was defined by the mesial and distal papillary midline and the mucogingival line from $0.5 \mathrm{~mm}$ to $5 \mathrm{~mm}$ in the apical direction (Figure 4). Since the volume was different for each patient, the mean value of the horizontal distance between the superimposed digital casts was measured. The mean and standard deviation of the distance were calculated.

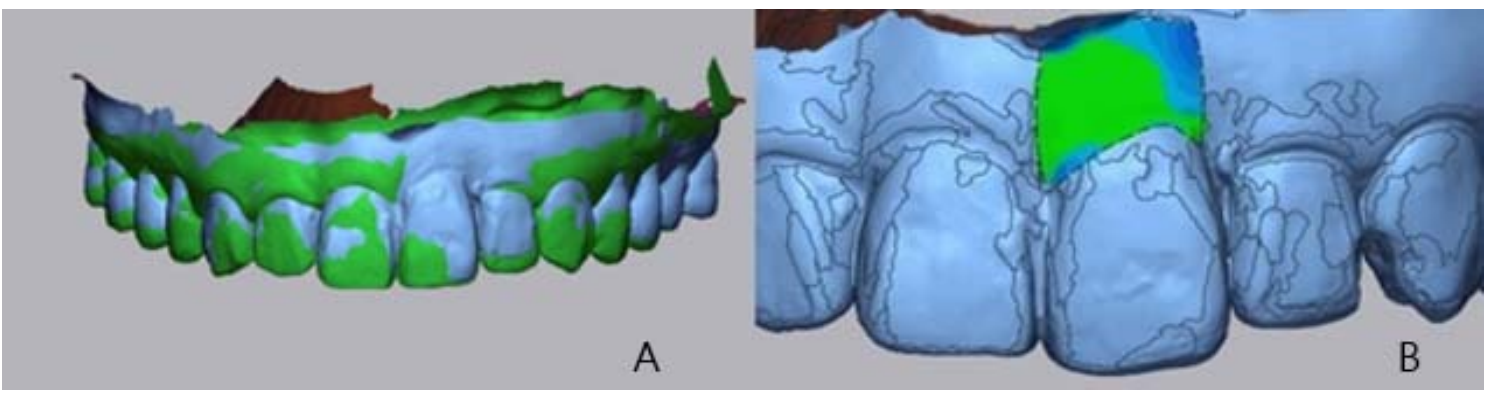

Figure 4. The Evaluation of the Labial Tissue Volume Change. (A) The Superimposed Digital Study Cast Model and Follow-Up Cast, (B) The Area of Interest, Where the Green Area Means No Change, and the Blue Area Means Loss of Volume.

A clinical photograph was used to evaluate the interdental papilla between the implant restoration and the adjacent teeth using the Jemt's index (score 0: no papilla is present, score 1: less than half of the papilla is present, score 2: more than half of the papilla is present, score 3: the papilla fills the entire interdental space, and score 4: the papilla is present) [26]. All measurements were performed by one clinician. 


\subsection{Esthetic Outcome}

The pink esthetic score (PES) was used to evaluate the esthetic outcomes with the clinical photographs before the treatment and after the follow-up period. The PES index includes seven variables (the mesial papilla, the distal papilla, the midfacial level, the midfacial contour, the alveolar process deficiency, the soft tissue color, and the soft tissue texture), and was assessed by using a 0-1-2 score, with $0=$ lowest score, and $14=$ highest score. All assessments were performed by one clinician [27].

\subsection{Statistical Analysis}

The significance of the changes in soft tissue dimension, interdental papilla, and PES was determined using a paired T-test for the parametric data and a Wilcoxon signed-rank test for the nonparametric data. The analysis was performed using the SPSS ver. 23.0 (SPSS Inc.) and the significance level was set at $5 \%$.

\section{Results}

The 13 patients who had been treated from April 2017 to May 2018 consisted of five males and eight females with a mean age of 49.6 years, and they were all included in the study. A total of 13 maxillary anterior teeth were immediately implanted and immediately restored, which included nine central incisors, two lateral incisors, and two canine teeth. The most prevalent reason for tooth loss was crown fracture, followed by caries, and periodontal disease. All patients were non-smokers. The mean follow-up period was 14.7 months, and the minimum follow-up period was one year. There was no loss of implant or pathology associated with the implants observed during the follow-up period.

\subsection{Soft Tissue Dimension}

Table 1 depicts the changes in the soft tissue dimension before the extraction and after the recent follow-up. There was no statistically significant change in the midfacial mucosa ( $p$-value: 0.028 ). The loss of the mesial papillary height was $0.32 \pm 0.83 \mathrm{~mm}$ ( $p$-value 0.203 ), and of the distal papillary height, $0.10 \pm 0.060 \mathrm{~mm}$ ( $p$-value: 0.594$)$. The mean horizontal change in the midfacial soft tissue volume was $0.32 \pm 0.83 \mathrm{~mm}$.

Table 1. The Changes in the Soft Tissue Dimension.

\begin{tabular}{ccc}
\hline Parameters & Amounts of Change & $p$-Value \\
\hline Midfacial mucosa level & $0.27 \pm 0.42$ & 0.028 \\
Mesial papilla level & $0.32 \pm 0.83$ & 0.203 \\
Distal papilla level & $0.10 \pm 0.06$ & 0.594 \\
Mean \pm standard deviation & $0.32 \pm 0.83$ & 0.060 \\
& & \\
\hline
\end{tabular}

\subsection{Jemt's Index}

There was no significant difference in the mesial and distal papilla index between the measurements made prior to the extraction and at one year of follow-up, according to the Wilcoxon signed-rank test ( $p$-value: $0.180,0.157)$ (Table 2).

Table 2. The Jemt's Index.

\begin{tabular}{ccc}
\hline Parameters & Amounts of Change & $p$-Value \\
\hline Mesial papilla & $-1.342^{*}$ & 0.180 \\
Distal papilla & $-1.414^{*}$ & 0.157 \\
\hline & ${ }^{*}$ Z value.
\end{tabular}




\subsection{PES}

The mean and standard deviation of the PES and of each variable are depicted in Table 3. The overall score was $11.16 \pm 2.17$ before treatment, and $10.25 \pm 1.42$ after the follow-up period. There were two cases with a total score of 8 or less in both the pre-operative and follow-up periods, which can be regarded as esthetic failures.

Table 3. The Pink Esthetic Score.

\begin{tabular}{cccc}
\hline PES Parameter & Pre-Operative & Follow-Up & $p$-Value \\
\hline Mesial papilla & $1.33 \pm 0.49$ & $1.25 \pm 0.45$ & 0.586 \\
Distal papilla & $1.42 \pm 0.51$ & $1.58 \pm 0.51$ & 0.438 \\
Midfacial mucosa level & $1.67 \pm 0.65$ & $1.42 \pm 0.51$ & 0.117 \\
Midfacial contour & $1.58 \pm 0.51$ & $1.33 \pm 0.49$ & 0.191 \\
Alveolar process deficiency & $1.33 \pm 0.78$ & $1.16 \pm 0.72$ & 0.504 \\
Soft tissue color & $1.58 \pm 0.51$ & $1.42 \pm 0.51$ & 0.339 \\
Soft tissue texture & $1.50 \pm 0.52$ & $1.42 \pm 0.51$ & 0.586 \\
Total score & $10.58 \pm 1.97$ & $9.83 \pm 1.34$ & 0.137 \\
\hline
\end{tabular}

\section{Discussion}

The immediate tooth replacement and the provisional restoration procedures provide a physiologic and esthetic advantage over the traditional delayed implant placement and prosthetic restoration [28]. From a clinical point of view, the post-extraction healing and osseointegration occur simultaneously, which is advantageous in terms of time. The current study suggests that the immediate post-extraction implant placement and provisional restoration in the esthetic zone yield acceptable changes in the soft tissue [8-13].

The immediate provisional restoration after an implant placement in the maxillary anterior dentition produces predictable results by maintaining the gingival papilla and facial gingival heights [29]. The gingival mucosa around the implant can heal along the contour of the interim restoration [30]. Maintaining the anatomic architecture of the existing extraction socket is an important factor in achieving esthetic results with the immediate placement and immediate restoration in the esthetic zone. A variety of immediate provisionalization methods have been attempted to obtain desirable emergence profiles [31-34].

With the developments in digital implant dentistry, a CAD/CAM system can be used to make the stereolithographic guides and customized abutments, as well as the final prostheses [35]. The stereolithographic guides used in this study (Oneguide, Osstem, Korea) were designed by superimposing the scanned data of the cast and by CBCT imaging using a CAD/CAM software (Implant Studio, 3Shape, Copenhagen, Denmark). The implant-supported prosthesis was planned from the scanned cast data, and the location and size of the fixture to be placed were chosen with the consideration of the alveolar bone and its adjacent anatomical structures on the $\mathrm{CBCT}$ data. A titanium customized abutment was designed by the CAD/CAM software (Dental System, 3Shape, Copenhagen, Denmark) duplicating the anatomical contours of the pre-existing tooth.

A guided surgery in combination with a pre-fabricated customized abutment can preserve the anatomic gingival architecture, minimizing the change in soft tissue. Current studies report that a peri-implanted soft tissue can heal according to the contours of the provisional restoration [36,37]. In this study, a titanium abutment replicating the original gingival shape before the extraction was pre-fabricated using a CAD/CAM system. On the day of surgery, the titanium anatomic abutments were connected to allow soft tissue healing and contouring along the original gingival shape. The customized anatomic abutment provides a reconstruction of the emergence profile and a gingival architecture to optimize the esthetic appearance. It also provides a custom seal to allow the graft material applied between the fixture and the bone gap to remain stable, without an exposure to the oral cavity (Figures 5 and 6). An additional advantage includes fewer complications from food retention and plaque 
deposition between the gingiva and the abutment. In a systematic review, Peace et al. reported that the surface of the abutment affects the tissue of the peri-implant. From an histological point of view, machined titanium abutments provide a low risk of inflammatory reactions that interfere with the healing of soft tissue [38].
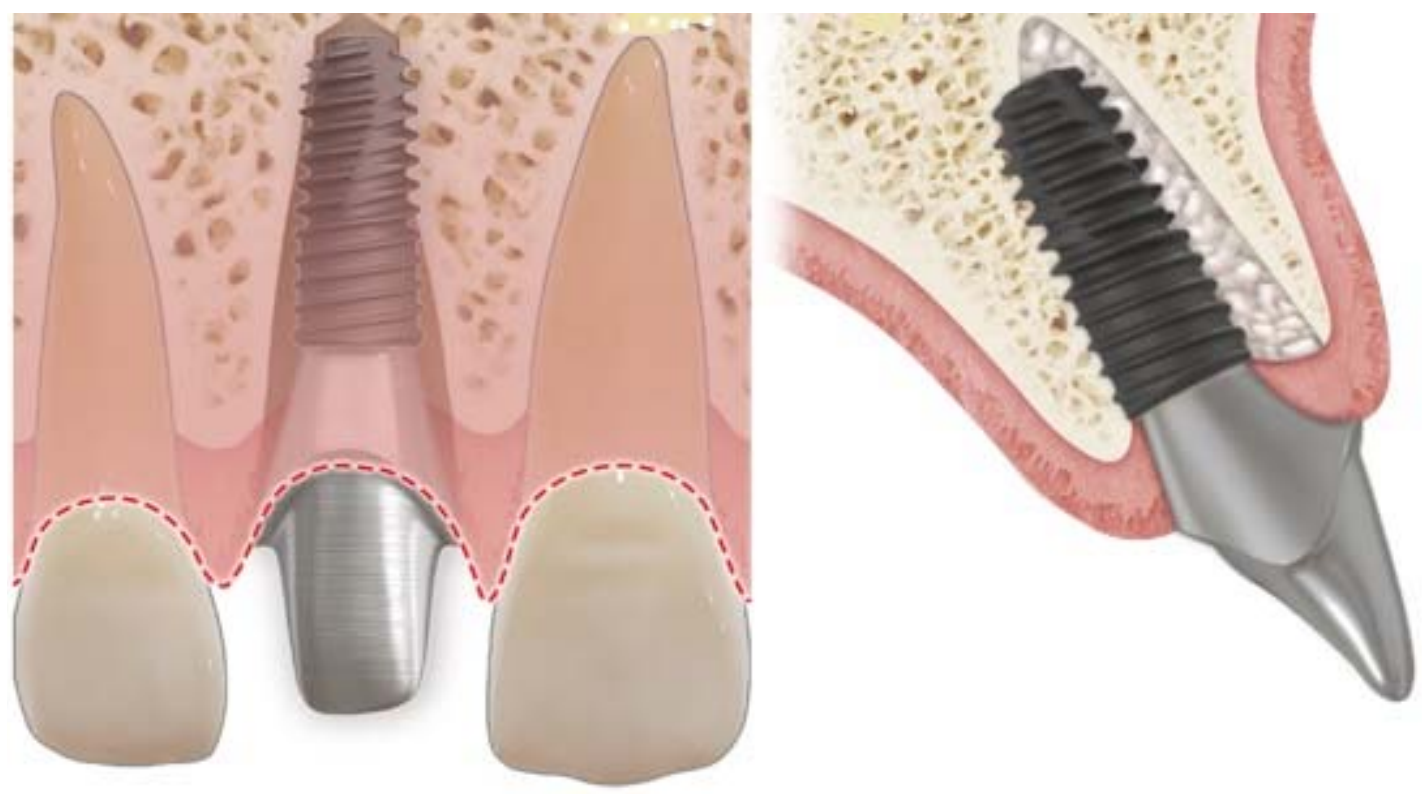

Figure 5. The Reconstruction of the Emergence Profile and Gingival Architecture with the Equi-Gingival Abutment Margin.

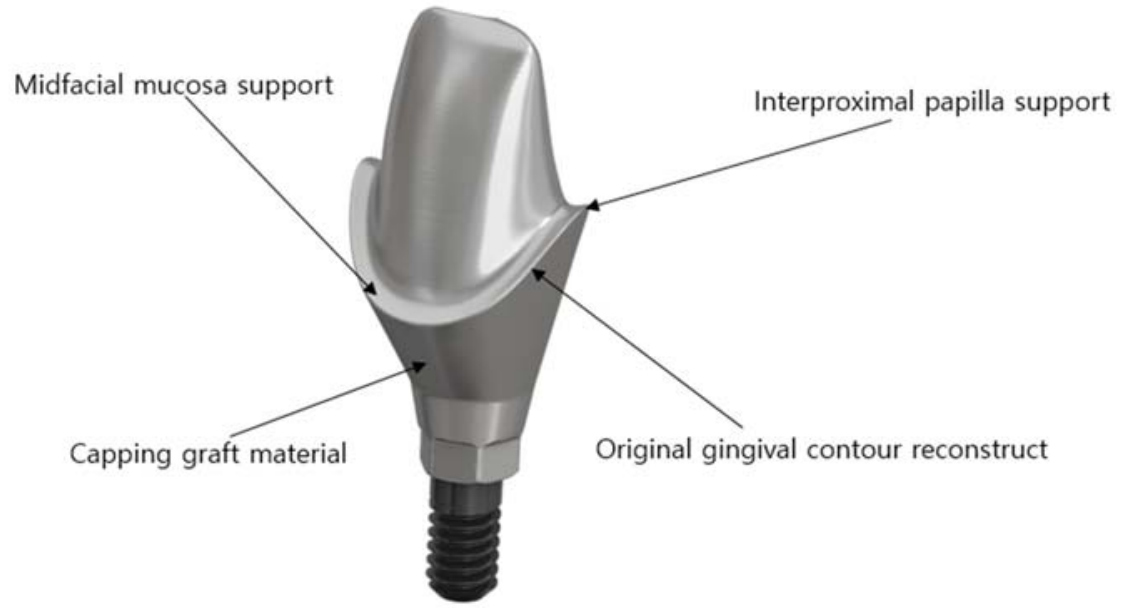

Figure 6. The Customized Titanium Anatomic Abutment Schematic Representation.

The results of present study show the stability of soft tissue in the pre-operative period and after a minimum of one year of follow-up. There was no significant recession of the midfacial mucosa; the recession of the mesial papillary height was $0.32 \mathrm{~mm}$, and the recession of the distal papillary height was $0.10 \mathrm{~mm}$. The mean horizontal change of the labial mucosa was $0.32 \pm 0.83 \mathrm{~mm}$. De Rouck et al. reported that the midfacial recession was $0.53 \mathrm{~mm}$ in average in patients who received single immediate implant and provisionalization in the anterior maxilla during the first year of function [8]. Khzam et al. evaluated the esthetic outcome by analyzing the dimensional changes of the midfacial soft tissue as a result of using the immediate placement and restoration protocol, and reported that advanced soft tissue recession $(>1 \mathrm{~mm}$ ) was observed in $11 \%$ of the cases [39]. Tian et al. evaluated changes in the contour of the labial soft tissue after an immediate post-extraction implant placement and provisionalization. During a one-year follow-up period, the labial soft tissue contour showed 
a continuous alteration. The total mean change was $0.62 \mathrm{~mm}$, mainly in the first three months [40]. The PES value before treatment was 11.16, and at one year of follow-up, 10.25. There was a slight decrease in each measurement and the existing esthetic status was found to have a significant effect on the outcome. In the present study, a favorable outcome was reported, which implies that the immediate restoration with the anatomic abutments provides predictable results regarding the stability of the soft tissue.

The evaluation of the stability of the soft tissue was intended to help support the scientific basis for the immediate restoration with a CAD/CAM customized titanium anatomic abutment using a guided surgery. With a retrospective study design, the present clinical study was limited by its small sample size, a relatively short observation period, and a lack of hard tissue evaluation. Future studies with a larger sample size, longer follow-up periods, and a prospective clinical trial design are needed to further support the findings of the present study.

\section{Conclusions}

The immediate post-extraction placement of an implant in the esthetic zone should satisfy the esthetic and functional demands. The clinical case series in the present study provides clinicians with a scientific basis for an immediate placement procedure using a 3D reconstruction stereolithographic guide and restoration protocols with a CAD/CAM titanium anatomic abutment. This advanced technique provides an option with predictable outcomes for the replacement of teeth in the esthetic zone.

Author Contributions: T.-H.K. and Y.-K.O. contributed to the acquisition, analysis, and interpretation of data for the work, E.C.K. and G.K.S., to the interpretation and critical revision, and C.-M.J. and Y.-D.K., to the conception and design of the work, and to the analysis and interpretation. All authors have read and agreed to the published version of the manuscript.

Funding: This work was supported by a 2-Year Research Grant of Pusan National University.

Conflicts of Interest: The authors declare no conflicts of interest.

\section{References}

1. Albrektsson, T. A multicenter report on osseo-integrated oral implants. J. Prosthet. Dent. 1988, 60, 75-84. [CrossRef]

2. Garber, D.A. The esthetic dental implant: Letting restoration be the guide. J. Am. Dent. Assoc. 1995, 12, 319. [CrossRef] [PubMed]

3. Sclar, A.G. Strategies for management of single-tooth extraction sites in aesthetic implant therapy. J. Oral Maxillofac. Surg. 2004, 62, 90. [CrossRef] [PubMed]

4. Mohr, A.S. An extreme makeover: Aesthetic demands and patient satisfaction. Dent. Today 2005, $24,56$.

5. Novaes, A.B.; Suaid, F.; Queiroz, A.C.; Muglia, V.A.; Souza, S.L.; Palioto, D.B.; Taba, M.; Grisi, M.F. Buccal bone plate remodeling after immediate implant placement with and without synthetic bone grafting and flapless surgery: Radiographic study in dogs. J. Oral Implantol. 2012, 38, 687-698. [CrossRef]

6. Kan, J.Y.; Rungcharassaeng, K.; Lozada, J. Immediate placement and provisionalization of maxillary anterior single implants: 1-year prospective study. Int. J. Oral Maxillofac. Implants 2003, 18, 31-39.

7. Buser, D.; Martin, W.; Belser, U.C. Optimizing esthetics for implant restorations in the anterior maxilla: Anatomic and surgical considerations. Int. J. Oral Maxillofac. Implants 2004, 19, 43-61.

8. De Rouck, T.; Collys, K.; Cosyn, J. Immediate single-tooth implants in the anterior maxilla: A 1-year case cohort study on hard and soft tissue response. J. Clin. Periodontol. 2008, 35, 649-657. [CrossRef]

9. De Rouck, T.; Collys, K.; Wyn, I.; Cosyn, J. Instant provisionalization of immediate single-tooth implants is essential to optimize esthetic treatment outcome. Clin. Oral Implants Res. 2009, 20, 566-570. [CrossRef]

10. Khzam, N.; Mattheos, N.; Roberts, D.; Bruce, W.L.; Ivanovski, S. Immediate placement and restoration of dental implants in the esthetic region: Clinical case series. J. Esthet. Restor. Dent. 2014, 25, 332-344. [CrossRef]

11. Tsuda, H.; Rungcharassaeng, K.; Kan, J.Y.; Roe, P.; Lozada, J.L.; Zimmerman, G. Peri-implant tissue response following connective tissue and bone grafting in conjunction with immediate single-tooth replacement in the esthetic zone: A case series. Int. J. Oral Maxillofac. Implants 2011, 26, 427-436. [PubMed] 
12. Brown, S.D.; Payne, A.G. Immediately restored single implants in the aesthetic zone of the maxilla using a novel design: 1-year report. Clin. Oral Implants Res. 2011, 22, 445-454. [CrossRef] [PubMed]

13. Cosyn, J.; De Bruyn, H.; Cleymaet, R. Soft tissue preservationand pink aesthetics around single immediate implant restorations: A 1-year prospective study. Clin. Implant. Dent. Relat. Res. 2013, 15, 847-857. [CrossRef] [PubMed]

14. Botticelli, D.; Berglundh, T.; Lindhe, J. Hard-tissue alterations following immediate implant placement in extraction sites. J. Clin. Periodontol. 2004, 31, 820-828. [CrossRef]

15. Hämmerle, C.H.; Chen, S.T.; Wilson, T.G., Jr. Consensus statements and recommended clinical procedures regarding the placement of implants in extraction sockets. Int. J. Oral Maxillofac. Implant. 2004, 19, 26-28.

16. Araujo, M.G.; Linder, E.; Lindhe, J. Bio-Oss collagen in the buccal gap at immediate implants: A 6-month study in the dog. Clin. Oral Implants Res. 2011, 22, 1-8. [CrossRef]

17. Tarnow, D.P.; Chu, S.J.; Salama, M.A.; Stappert, C.F.J.; Salama, H.; Garber, D.A.; Sarnachiaro, G.; Sarnachiaro, E.; Gotta, S.; Saito, H. Flapless post extraction socket implant placement in the esthetic zone: Part 1. The effect of bone grafting and/or provisional restoration on facial-palatal redge dimension change-a retrospective cohort study. Int. J. Periodontics Restor. Dent. 2014, 34, 323-331. [CrossRef]

18. Tiziano, T.; Tommaso, W.; Fabio, S.; Hom-lay, W.; Giovanni, Z. Implant placement in the esthetic area: Criteria for positioning single and multiple implants. Periodontology 2000 2018, 77, 176-196.

19. Choi, S.K. Digital technologies for restorative care; Part 1. Decis. Dent. 2018, 4, 33-36.

20. Hammerle, C.; Stone, P.; Jung, R.E.; Kapos, T.; Brodala, N. Consensus statements and recommended clinical procedures regarding computer-assisted implant dentistry. Int. J. Oral Maxillofac. Implants 2009, 24, $126-131$.

21. Sun, Y.; Lübbers, H.T.; Agbaje, J.O.; Schepers, S.; Politis, C.; Slycke, S.V.; Vrielinck, L. Accuracy of Dental Implant Placement Using CBCT-Derived Mucosa-Supported Stereolithographic Template. Clin. Implant Dent. Relat. Res. 2015, 17, 862-870. [CrossRef] [PubMed]

22. George, R. Deeb, How Accurate Are Implant Surgical Guides Produced with Desktop Stereolithographic 3-Dimentional Printers? J. Oral Maxillofac. Surg. 2017, 75, e1-e2559.

23. Mario, B.; Pier, P.P.; Silvia, P.; Sebastian, T.; Mattia, M.; Marco, C.; Carlo, M. Peri-implant soft tissue conditioning by means of customized healing abutment: A randomized controlled clinical trial. Materials 2019, 12, 18.

24. Kyung, C.O.; Jeongwon, P.; Hee-Hwan, K. Esthetic rehabilitation of maxillary anterior teeth, including an immediate provisionalization with an implant-supported fixed dental prosthesis. J. Clin. Med. 2019, $28,8$.

25. Dingxiang, Y.; Xin, W.; Su, C. Vertical and horizontal dimensional changes of peri-implant facial bone following immediate placement and provisionalization with customized definite abutment in maxillary anterior single implants. Clin. Oral Implants Res. 2019, 30, 387.

26. Jemt, T. Regeneration of gingival papillae after single-implant treatment. Int. J. Periodontics Restor. Dent. 1997, 17, 326-333.

27. Fürhauser, R.; Florescu, D.; Benesch, T.; Haas, R.; Mailath, G.; Watzek, G. Evaluation of soft tissue around single tooth implant crowns: The pink esthetic score. Clin. Oral Implants Res. 2005, 16, 639-644. [CrossRef]

28. Atieh, M.A.; Payne, A.G.; Duncan, W.J.; Cullinan, M.P. Immediate restoration/loading of immediately placed single implants: Is it an effective bimodal approach? Clin. Oral Implants Res. 2009, 20, 645-659. [CrossRef]

29. Furze, D.; Byrne, A.; Alam, S.; Wittneben, J.G. Esthetic outcome of implant supported crowns with and without peri-implant conditioning using provisional fixed prosthesis: A randomized controlled clinical trial. Clin. Implant Dent. Relat. Res. 2016, 18, 1153-1162. [CrossRef]

30. Lewis, S. Anterior single-tooth implant restorations. Int. J. Periodontics Restorative Dent. 1995, 15, 31-41.

31. Tselios, N.; Parel, S.M.; Jones, J.D. Immediate placement and immediate provisional abutment modeling in anterior single-tooth implant restorations using a CAD/CAM application: A clinical report. J. Prosthet. Dent. 2016, 95, 181-185. [CrossRef]

32. Bruno, V.; O'Sullivan, D.; Badino, M.; Catapano, S. Preserving soft tissue after placing implants in fresh extraction sockets in the maxillary esthetic zone and a prosthetic template for interim crown fabrication: A prospective study. J. Prosthet. Dent. 2014, 111, 195-202. [CrossRef] [PubMed]

33. Lin, W.S.; Harris, B.T.; Morton, D. Use of implant-supported interim restorations to transfer periimplant soft tissue profiles to a milled polyurethane definitive cast. J. Prosthet. Dent. 2013, 109, 333-337. [CrossRef]

34. Akin, R. A new concept in maintaining the emergence profile in immediate posterior implant placement: The anatomic harmony abutment. J. Oral Maxillofac. Surg. 2016, 74, 2385-2392. [CrossRef] [PubMed] 
35. Fuster-Torres, M.A.; Albalat-Estela, S.; Alcañiz-Raya, M.; Peñarrocha-Diago, M. CAD/CAM dental systems in implant dentistry: Update. Med. Oral Patol. Oral Cir. Bucal. 2009, 14, e141-e145.

36. Saito, H.; Chu, S.J.; Reynolds, M.A.; Tarnow, D.P. Provisional restorations used in immediate implant placement provide a platform to promote peri-implant soft tissue healing: A pilot study. Int. J. Periodontics Restor. Dent. 2016, 36, 47-52. [CrossRef] [PubMed]

37. Periklis, P. Immediate provisionalization with a CAD/CAM interim abutment and crown: A guided soft tissue healing technique. J. Prosthet. Dent. 2015, 113, 91-95.

38. Pesce, P.; Menini, M.; Tommasato, G.; Patini, R.; Canullo, L. Influence of modified titanium abutment surface on peri-implant soft tissue behavior: A systematic review of histological findings. Int. J. Oral Implantol. 2019, 12, 419-429.

39. Khzam, N.; Arora, H.; Kim, P.; Fisher, A.; Mattheos, N.; Ivanovski, S. Systematic review of soft tissue alterations and esthetic outcomes following immediate implant placement and restoration of single implants in the anterior maxilla. J. Periodontol. 2015, 86, 1321-1330. [CrossRef]

40. Tian, J.; Wei, D.; Zhao, Y.; Di, P.; Jiang, X.; Lin, Y. Labial soft tissue contour dynamics following immediate implants and immediate provisionalization of single maxillary incisors: A 1-year prospective study. Clin. Implant Dent. Relat. Res. 2019, 21, 492-502. [CrossRef]

(C) 2020 by the authors. Licensee MDPI, Basel, Switzerland. This article is an open access article distributed under the terms and conditions of the Creative Commons Attribution (CC BY) license (http://creativecommons.org/licenses/by/4.0/). 